\title{
MULHERES, NATUREZA MAIS-QUE-HUMANA E MOVIMENTOS TRANSCORPÓREOS EM CONTOS DE FADAS DE MARINA COLASANTI
}

\author{
WOMEN, MORE-THAN-HUMAN NATURE AND TRANSCORPOREAL MOVEMENTS IN MARINA COLASANTI'S \\ FAIRY TALES
}

\section{RESUMO}

Neste trabalho, argumento que as personagens femininas e a natureza mais-quehumana dos contos de fadas de Marina Colasanti sofrem violências correlatas, executadas por personagens masculinas representativas da cultura capitalpatriarcal. As personagens oprimidas, no entanto, resistem a essa hostilidade a partir de metamorfoses, que podem ser lidas, metaforicamente, como movimentos transcorpóreos, capazes de ressignificar a concepção das mulheres e da natureza, ambas consideradas passivas e aptas à exploração, pelo patriarcado. Sobre um possível essencialismo nessa interconexão, argumento que a autora usa-o de modo estratégico. O trabalho, portanto, desenvolve-se na esteira da ecocrítica feminista.

Palavras-chave: Marina Colasanti. Contos de fada. Mais-que-humano. Transcorporalidade. Ecocrítica feminista.

\begin{abstract}
In this paper, I argue that the female characters and the more-than-human nature in the fairy tales by Marina Colasanti suffer corelated violence, performed by male characters representative of the capital-patriarchal culture. However, the oppressed characters resist this hostility through metamorphosis, which can be read, metaphorically, as transcorporeal movements capable of resignifying the concept of woman and nature, both considered as passive and apt to exploration by the patriarchy. Regarding a possible essentialism in this interconnection, I argue that the author uses it in a strategic way. Thus, this paper is developed on the heels of feminist ecocriticism.
\end{abstract}

Keywords: Marina Colasanti. Fairy Tales. More-than-Human. Transcorporeality. Feminst Ecocriticism.

A utopia dos feminismos projeta a consciência do humano, livre dos binarismos de gênero e das diferenças de raça e etnia, de classe e de qualquer outro traço que favoreça a hierarquia e, consequentemente, a opressão entre os seres. Toril Moi, num artigo de 1985, em que defende, sob a perspectiva do desconstrucionismo derridiano,

Edilane Ferreira da Silva

Universidade Federal de Alagoas (UFAL). Email: edilaneferreira@msn.com 
a contribuição da escritora Virgínia Woolf para os estudos feministas - contrapondose, dessa forma, à crítica de Elaine Showalter ${ }^{1}$-, afirma que “[...] ainda é politicamente essencial para as feministas defenderem as mulheres como mulheres para contrariar a opressão patriarcal que exatamente despreza as mulheres como mulheres" (Moi, 2017: 295). Gayatri Chakravorty Spivak, não obstante, em seu Pode o subalterno falar? (1985), argumenta que o uso de um essencialismo estratégico, identitário e provisório ainda é necessário para algumas conquistas. Diana Fuss compartilha da mesma defesa num texto de 1989, ao desvelar o binarismo essencialismo/construcionismo, demonstrando que há essencialismo até mesmo na égide do construcionismo, e assumindo "o risco da essência", também de forma contingencial.

Embora tenham ocorrido significativos avanços teórico-críticos no campo da crítica feminista, como podemos constatar, eles ainda não foram suficientes para que os anseios há pouco citados saíssem do plano da utopia. Assim, ainda que tenham sido formuladas na década de 1980, as colocações de Moi, Spivak e Fuss continuam pertinentes. Se, neste século, reconhecer-se em categorias como mulher, gay, trans ou queer ainda é importante, na década de 1970, período em que o conceito de mulher, os espaços a ela destinados e a opressão do seu corpo foram especialmente questionados - mesmo que de modo universal e essencialista $-^{2}$, hastear a bandeira de gênero estava na ordem do dia, apesar de esse conceito ter sido estabelecido apenas nos anos 1980. É nessa seara que a escritora Marina Colasanti lança o seu primeiro livro categorizado como conto de fadas, Uma ideia toda azul, publicado em 1979. As narrativas dessa obra e das ulteriores - a exemplo de Longe como o meu querer (1997) e Do seu coração partido (2009), consideradas neste trabalho - giram em torno de personagens construídas assimetricamente, dos gêneros feminino e masculino. Nos contos aqui analisados, via de regra, as mulheres são os sujeitos oprimidos, ao passo que os homens são os opressores.

Neste artigo, analiso três contos de fadas de Colasanti, pertencentes às obras mencionadas acima. Neles, as mulheres resistem às violências impostas, a partir das conexões que mantêm com a natureza mais-que-humana, expressão que Stacy Alaimo (2017) usa intercambiada com não humano. No entanto, o termo mais-quehumano propõe uma compreensão que retira o humano do centro e desfaz oposições como a sugerida pelo uso do não humano (existe o humano e todo o resto é não humano), sustentando que há vidas e corpos para além do humano: árvores, plantas, bichos, insetos, fungos, bactérias, vírus, lua etc. Esse humano, por sua vez, “[...] está sempre enredado com o mundo mais-que-humano" (Alaimo, 2017: 910), já que ele próprio - com as demais naturezas - integra a Natureza, isto é, a totalidade. Dito de outra forma, o mais-que-humano apresenta uma dimensão não antropocêntrica. As resistências, nos contos analisados, ocorrem por meio de metamorfoses, as quais

1 Para Showalter, Um quarto todo seu não pode ser figurado como um ensaio feminista, já que não assume a experiência - o "pessoal é político", dos anos 1970 - e não dá vazão à raiva, pelos anos a fio de reificação da mulher.

2 Cf. os trabalhos referentes aos anos 1970, da primeira parte da antologia Traduções da cultura: perspectivas críticas feministas (1970-2010), de Brandão et al. (2017). 
leio também como a retomada de um lado instintual, ou selvagem, feminino, o qual abordarei melhor adiante. As narrativas evidenciam que, através da reconexão com essa natureza selvagem, é possível uma emancipação que confronta a cultura hegemonicamente patriarcal. Assim, esses contos de fadas podem ser lidos como essencialistas.

Izabel Brandão, num artigo que aborda o ecofeminismo como um viés crítico para os estudos literários no Brasil, cita críticas que discutem a relação mulheres/ natureza "[...] dentro de uma perspectiva que mostra que essa ligação pode ser buscada de modo libertador" (Brandão, 2003:464), como é o caso de Karla Armbruster, Ynestra King e Susan Griffin. Além disso, nesse texto, Brandão apresenta Alaimo como crítica cujo argumento propõe a redefinição de natureza e de mulheres, sendo essa natureza considerada um espaço de possibilidade feminista. O ecofeminismo ou a ecocrítica feminista ${ }^{3}$ que, em linhas gerais, denuncia o paralelismo entre as violências praticadas contra as mulheres e contra a natureza mais-que-humana, é, pois, a perspectiva teórico-crítica utilizada para as minhas análises. Todavia, considerando esse realinhamento - tomando de empréstimo a expressão de Mary Russo (2000) - da relação mulheres/natureza proposto pelo ecofeminismo e fundamentada nas teorizações de Spivak e Fuss, argumento que a autora promove um essencialismo estratégico, evocado, especialmente, na construção da personagem feminina e da natureza mais-que-humana não subordinadas, bem como nos finais abertos das narrativas, que não encerram os contos numa única interpretação.

A consideração da agência da materialidade nas narrativas, a partir do enfoque na corporalidade da mulher em contato com a corporalidade mais-que-humana, é também uma estratégia que ressignifica a construção cultural de que tanto a natureza quanto as mulheres são passivas e disponíveis para a exploração do homem. É nesse sentido que as formulações de Alaimo, sobre os feminismos transcorpóreos e o espaço ético da natureza, são importantes para este trabalho, já que, para ela, “[...] pensar através dos corpos pode catalisar o reconhecimento de que o 'ambiente', quase sempre imaginado como um espaço inerte e vazio ou como um 'recurso' para uso humano, é, de fato, um mundo de seres carnais, com suas próprias necessidades, exigências e ações" (Alaimo, 2017: 910). As mulheres, naturalizadas e oprimidas pela cultura hegemônica, numa leitura ecocrítica feminista, têm potencialidades para esse mesmo agenciamento. $\mathrm{Na}$ abordagem das metamorfoses envolvendo mulheres, elementos como a lua e animais mais-que-humanos, sinalizo que há uma metaforização dos movimentos transcorpóreos propostos por Alaimo (2017).

Contudo, é importante sublinhar que os contos de Colasanti, aqui considerados, figuram personagens míticas e extranaturais, logo, não biológicas. Por outro lado, as abordagens das teóricas referenciadas, a exemplo de Donna Haraway e Alaimo, não estão tratando de seres imaginários, mas daqueles aos quais podemos nos referir

3 Opto pela expressão ecocrítica feminista, ao invés de ecofeminismo, em concordância com o que argumenta Greta Gaard (2017), em relação ao espaço tangenciado do feminismo no campo da ecocrítica, e pelo fato também de as teóricas citadas neste trabalho não se autodenominarem ecofeministas, ainda que tratem da associação mulheres/natureza não humana ou mais-que-humana. 
como reais, palpáveis. As considerações que teço, portanto, sobre as relações entre as mulheres e a natureza mais-que-humana, estão no campo metafórico. Neste trabalho, o uso de conceitos como "relação interespécie" e "movimentos transcorpóreos" extrapola os seus contextos originais, porém, cabe perfeitamente à função alegórica que os contos de fadas, normalmente, desempenham.

\section{Movimentos transcorpóreos e resistências}

No conto "Entre as folhas do verde O" (1979), um príncipe, acompanhado por vassalos, cavalos e cães, vai à floresta caçar. Os animais conseguem se esconder, menos a corça-mulher: "Foi assim que o príncipe a viu. Metade mulher, metade corça, bebendo no regato. A mulher tão linda. A corça tão ágil. A mulher ele queria amar, a corça ele queria matar" (Colasanti, 1979: 39). E, de fato, ele a mata, mas não como um caçador. No primeiro sinal de vulnerabilidade, ele a captura e a leva para o castelo, trancando-a num quarto. Com a assiduidade dos encontros, ambos se apaixonam, embora haja dissonâncias: as linguagens são diferentes e não há, portanto, comunicação verbal. Porém, quando o príncipe a vê chorando, pensa que o desejo da corça-mulher é o mesmo que o dele. Então, chama o feiticeiro, que a transforma toda em mulher, erradicando, dessa maneira, o seu lado instintual.

Compreendo, aqui, o sentido de instinto com base na psicologia profunda de Carl Gustav Jung (1875-1961). Para o psicólogo, em "Instinto e inconsciente" (1919), instintos são formas típicas de comportamento, "[...] impulsos destinados a produzir ações que resultam de uma necessidade interior, sem uma motivação consciente" (Jung, 1984: 76). Eles, assim como os arquétipos - imagens primordiais, formas de apreensão que se repetem uniforme e regularmente, a partir das quais os instintos se manifestam -, constituem o inconsciente coletivo. Em outras palavras, a sua natureza é coletiva, universal, e não individual, ao passo que a sua ação ocorre por intermédio da intuição, que se trata de uma percepção também inconsciente. Leio esse lado instintual da personagem de Colasanti também fundamentada na psicóloga junguiana Clarissa Pinkola Estés, em Mulheres que correm com os lobos (1992). Segundo ela, a natureza instintiva é uma natureza psicológica, por traz da qual está o arquétipo da Mulher Selvagem, que emana do inconsciente coletivo de todas as mulheres. Esse é o arquétipo da mulher não domesticada, instintiva, intuitiva, que têm a "[...] liberdade para se movimentar, para falar, para ter raiva e para criar" (Estés, 2014: 50). É importante enfatizar, ainda com Estés (2014: 50), que “[...] o termo selvagem neste contexto não é usado em seu atual sentido pejorativo de algo fora de controle, mas em seu sentido original, de viver uma vida natural, uma vida em que a criatura tenha uma integridade inata e limites saudáveis". É essa mulher que o patriarcado e as personagens masculinas dos contos de Colasanti aqui considerados - representativos dessa cultura misógina e sexista - não admitem. 
Em “Debaixo da pele a lua” (1997), uma mulher, como o título sugere, tem a lua sob a pele. Quando essa lua está cheia, a luminosidade que emana da personagem é extrema, o que atrai homens com interesses diversos: porque ela era diferente das outras, e, assim, seria ideal para o homem mais rico da região; ou porque, também por ser "exótica", daria lucros a um ladrão, já que ele poderia exibi-la nas feiras. Nesse último caso, o homem "[...] prendeu a mulher ao pé da mesa com uma corrente [...]" (Colasanti, 1997: 48), após capturá-la.

Se no primeiro conto a violência contra a mulher está vinculada, diretamente, à sua identidade e, no segundo, à sua liberdade; no terceiro, a opressão se volta ao próprio direito de viver. O conto "Vermelho, entre os troncos" (2009), portanto, mimetiza o feminicídio. ${ }^{4}$

Os moços riem, se chamam, açulam os cães, e eles próprios se lançam, com seus cavalos, no encalço dessa nova caça. Inúteis os arbustos. Nada pode protegê-la. Ela foge, os cavaleiros a perseguem, depois deixam por um instante que se afaste, e quando está quase escapando, o mais belo dos caçadores ergue-se na cela. “É minha!", grita. Os outros retêm seus cavalos. Ele levanta a lança sobre a cabeça, e a arremessa (Colasanti, 2009: 72).

Esses cavaleiros adentram a floresta em busca de animais de grande porte, cuja carne será assada no castelo, conforme a narrativa. Nesse percurso, eles encontram uma mulher nua, banhando-se no rio, e, como a uma caça, atacam-na, não sem antes permitirem que ela sinta a ligeira esperança de que poderia escapar, como demonstra o trecho supracitado. Ela fica na floresta, e o ataque parece acontecer por uma espécie de prazer que os caçadores revelam, ao matá-la: "As outras caças serão levadas para o castelo, atravessadas sobre os cavalos, gotejando sangue. Essa não" (Colasanti, 2009: 72).

Essa estrutura recorrente, em que o homem é sempre o agressor e a mulher só assume o papel de vítima, desvela o caráter essencialista dessas narrativas, o que é intensificado pelo dualismo natureza/cultura, “[...] que povoa o imaginário de gênero, no qual a linguagem verbal é tida como essencialmente masculina, ficando a mulher no território do pré-simbólico e, portanto, excluída do discurso [...]", como aponta Susana Funck (2016: 336), ao analisar os contos "Entre as folhas do verde O", "Verdadeira história de um amor ardente", "A moça tecelã" e "Além do bastidor". Essa

\footnotetext{
4 É pertinente, a título de ilustração, mencionar a crítica que Breny Mendoza faz às teses de Dussel, no artigo "A epistemologia do sul, a colonialidade de gênero e o feminismo latino-americano". Conforme a autora, as categorias unitárias da categoria de "povo", defendidas pelo crítico, cuja orientação é masculinista, excluíram as mulheres (pobres, indígenas, afrodescendentes, lésbicas etc.) e, além disso, o paralelo com a teologia da libertação não considera os sofrimentos dessas mulheres. Citando Elina Vuola, Mendoza expõe que "[...] na teologia da libertação ficam fora a violência contra as mulheres, as violações e o assédio sexual, as mortes por abortos ilegais, a mortalidade materna e infantil, assim como os feminicídios" (768). O conto de Marina Colasanti - vale ressaltar, autora inserida no contexto latinoamericano -, portanto, alegoriza essa realidade opressiva e dá visibilidade à questão negligenciada por Dussel.
} 
linguagem está, obviamente, na esfera da cultura, enquanto a ausência dela é atribuída à natureza. No caso dos contos aqui selecionados, as personagens do sexo feminino não falam, o que caracteriza um contexto opressor de silenciamento das mulheres, alegorizado por Colasanti. Nas raras vezes em que há discurso direto - visto que a narrativa é em terceira pessoa, onisciente, com predominância do discurso indireto -, a discursividade está atrelada a personagens do sexo masculino, como ilustram os trechos dos contos "Debaixo da pele, a lua" e "Vermelho, entre os troncos": "Que belo dinheiro posso tirar dela exibindo-a nas feiras!', pensou faiscando seu olhar de gato" (Colasanti, 1997: 47) e “'É minha!, grita” (Colasanti, 2009: 72).

Uma passagem de "Entre as folhas do verde O" evidencia tanto os universos paralelos quanto o abismo linguístico entre as personagens, bem como o poder provisório - do homem por dominar a linguagem cultural:

Todos os dias o príncipe ia visitá-la. Só ele tinha a chave. E cada vez se apaixonava mais. Mas a corça-mulher só falava a língua da floresta e o príncipe só sabia ouvir a língua do palácio.

Então ficavam horas se olhando calados, com tanta coisa para dizer.

Ele queria dizer que a amava tanto, que queria casar com ela e tê-la para sempre no castelo, que a cobriria de roupas e jóias, que chamaria o melhor feiticeiro do reino para fazê-la virar toda mulher.

Ela queria dizer que o amava tanto, que queria casar com ele e

Essa incomunicabilidade, que, metaforicamente, podemos chamar de interespécie, num contraponto ao manifesto das espécies companheiras de Dona Haraway, é provocada pela dissonância "só falava" e "só sabia ouvir", relacionada aos extremos floresta - espaço livre, longe do controle da cultura, habitat da mulhercorça - e palácio - espaço controlado, patriarcal. Nesse sentido, há uma inversão e, portanto, uma subversão relacionada ao público e ao privado e às suas atribuições aos universos masculino e feminino, tema importante na agenda dos estudos feministas, especialmente nos debates dos anos 1970. Como Sherry B. Ortner evidencia, criticamente, em seu antológico artigo "Está a mulher para o homem assim como a natureza para a cultura?" (1974), o papel social feminino foi limitado ao círculo doméstico sob o (equivocado e opressor) argumento das funções fisiológicas das mulheres, consideradas mais próximas da natureza. Elas, confinadas a uma função reprodutiva e de cuidado das crianças, foram inferiorizadas e desvinculadas da cultura. Por outro lado, nesse sistema, “[...] os homens são identificados não somente com a cultura [...], mas como se opondo à natureza; eles são identificados 
em particular com a cultura no sentido antigo da manifestação mais elevada do pensamento humano - arte, religião, leis etc." (Ortner, 2017: 109). Contudo, Ortner contesta, defendendo que esse trabalho doméstico é, também, um trabalho cultural, haja vista que são as mulheres quem preparam as crianças - meninos e meninas para a socialização, assim como transformam o alimento cru (natural) em cozido (cultural), o que questiona os limites da oposição natureza/cultura.

Ainda sobre o excerto do conto de Colasanti, a personagem masculina, embora apta à escuta, está fechada aos seus pares. Ela se mostra incapaz de realizar a "escuta cuidadosa do outro", mencionada por Greta Gaard (2017: 801), na abordagem da ecopsicologia interespécie, vista como um desdobramento a ser considerado pelas ecofeministas e ecocríticas feministas. Fechada em sua espécie, não há comprometimento ético com a "alteridade significante" defendida por Haraway (2017: 729). O Outro, o diferente, torna-se insignificante.

Convém, no entanto, observar os verbos falar e ouvir atribuídos às personagens. Associado ao ouvir, está o verbo saber, que sugere a noção de racionalidade defendida pela cultura, mas totalmente ignorante em relação a outras formas de agenciamento. O homem não sabia porque o patriarcado assim o orienta. Por outro lado, a mulher "só falava a língua da floresta”. Não há, nessa construção, qualquer marca de instrução. Ela, "naturalmente", falava. Nesse aspecto, a ação da mulher não é passiva. Afinal, ouvir exige menos ação que falar. Os últimos períodos demonstram a deslegitimação dessa voz - "não cultural": o segredo da palavra, negado à mulher, e a chave da porta, exclusiva do homem, servem como metáforas do poder hegemonicamente patriarcal e da posição de subalternidade imposta à mulher, já que, como conclui Spivak (2010: 126), "[o] subalterno não pode falar. Não há valor algum atribuído à 'mulher' como um item respeitoso nas listas de prioridades globais".

A consideração da ligação mulheres/natureza foi rejeitada pela teoria feminista de orientação pós-estruturalista, fundamentada no construcionismo social. Alaimo evidencia, criticamente, o esforço do feminismo para "liberar" as mulheres da natureza, pois essa vinculação, para a cultura ocidental, representa(va) estar "[...] alijada do domínio da transcendência, da racionalidade, da subjetividade e do agenciamento humanos [...]" (Alaimo, 2017: 911). A natureza, nessa perspectiva, foi compreendida como um "repositório de essencialismo e stasis". É exatamente como contraponto a essa visão que o argumento de Alaimo se assenta, a partir da proposta de redefinição dos dualismos marcados pelo gênero - a exemplo dos corpos femininos, da natureza e da cultura -, com base na noção de transcorporalidade, que, "[...] como um locus teórico, é um lugar em que as teorias corpóreas e ambientais se encontram e se misturam de forma produtiva” (Alaimo, 2017: 910).

Essa acepção negativa da aproximação mulheres/natureza, como já ressaltado, foi pertinentemente questionada por Ortner. No trabalho, a autora universaliza a subordinação das mulheres na cultura, considerando esse fato pancultural, o que, evidentemente, gerou críticas. Porém, algumas colocações foram (são) absolutamente pertinentes para o entendimento de que os conceitos de cultura e de natureza se tratam de construções culturais. As mulheres foram julgadas como mais próximas da 
natureza devido ao corpo que possuem e às funções que ele exerce, aos papéis sociais determinados por esse corpo - mais especificamente, restritos ao espaço doméstico - e à estrutura psíquica feminina, considerada não apenas diferente, mas inferior, já que, nessa compreensão, não possui aptidões culturais, como a capacidade de transcendência. Na percepção de Alaimo, o problema não está nessa vinculação das mulheres com a natureza, mas em como essa natureza - e, portanto, o material - foi construída e associada às mulheres. Assim, a pesquisadora conclui:

Se vamos entender a natureza como algo que não seja apenas um recurso passivo para a exploração do Homem, e se vamos entender o corpo humano como algo além de uma tabula rasa aguardando a inscrição da cultura, temos que reconceituar corpos e naturezas de forma a reconhecer suas ações (Alaimo, 2017: 916).

É essa agência dos corpos femininos e da natureza mais-que-humana que leio nos contos de fadas de Marina Colasanti em questão. Neles, a personagem feminina permanece vinculada ao mais-que-humano, representado pela corça, pela lua e pela loba, ao passo que os homens se mantêm ligados à cultura, a partir do manuseio de ferramentas para a caça e da "domesticação" de animais, a exemplo de cavalos e cães, além, sobretudo, do domínio da palavra, como exemplifica a passagem, já evidenciada, do conto "Entre as folhas do verde O". Em outros termos, há duas perspectivas de relação envolvendo personagens femininas, masculinas e o maisque-humano: no que diz respeito ao homem, há distanciamento e opressão. O maisque-humano é considerado passivo, o Outro a ser explorado; em relação à mulher, há interconexão. O mais-que-humano é tão natureza quanto a mulher. E, a partir do recurso da metamorfização, corporificam-se numa única matéria.

Há, pois, a representação da transcorporalidade, i. e., “[...] o tempo-espaço em que a corporalidade humana, em toda sua carnalidade material, é inseparável da 'natureza' ou do 'ambiente"' (Alaimo, 2017: 910). Alaimo argumenta que, dessa "zona de contato", emergem possibilidades éticas e políticas. No caso da aproximação mulheres/natureza, reinscrita por Colasanti, são mobilizadas tanto questões éticas quanto políticas, que devem ser consideradas: as relações entre humanos gendrados e o mais-que-humano, do mesmo modo que a problematização das opressões dirigidas às mulheres e à natureza, com desfechos centrados na resistência de ambas. A autora corre o "risco da essência", para usar a expressão de Fuss (2017:391), mas vai além do essencialismo simplista, uma vez que recorre a essa conexão visando à agência das mulheres e do mais-que-humano.

Funck (2016: 336), em sua crítica, conclui que, “[...] [a]o rejeitar seu corpo de mulher, a personagem feminina prefere o risco de ser morta pelo príncipe-caçador, a ser transformada em mulher conforme o desejo de um homem" e, nesse sentido, contribui significativamente para as discussões em torno do corpo feminino. Quanto à vinculação da mulher com a natureza mais-que-humana, considero, também, que há avanços pertinentes: ao admitir o movimento transcorpóreo, a narrativa 
ressignifica a concepção da natureza, que não é vista como stasis, "[...] associada à corporalidade, falta de intelecto e passividade" (Alaimo, 2017: 911-912), mas como um locus de resistência e de possibilidades de agenciamento da mulher - diferente daquela construída pela cultura capital-patriarcal5 - e do mais-que-humano oprimidos. Assim, o que ocorre é um realinhamento, nos termos de Russo (2000), ou seja, um uso afirmativo dessa conexão. É a partir da vinculação com o ambiente natural, realinhado, por meio de movimentos transcorpóreos, que as mulheres - e, igualmente, a natureza mais-que-humana - (re)agem.

A corça-mulher, do conto "Entre as folhas do verde O", quando acordou e se viu toda mulher, “[...] duas pernas só e compridas, um corpo todo branco" (Colasanti, 1979: 40), não conseguiu se levantar. O príncipe a auxiliou, contratando profissionais que lhe ensinassem a andar e oferecendo roupas e joias apropriadas ao universo que ela deveria integrar. Porém, a (agora só) mulher permanecia sem a palavra “[...] [e] o desejo de ser mulher" (Colasanti, 1979: 40), na medida em que essa construção parte dos interesses do homem alinhado à cultura que hostiliza a natureza.

Apropriando-se da dimensão simbólica, caracterizadora do gênero conto de fadas, a narrativa explora sentidos do número sete que sugerem a individuação ${ }^{6}$ da personagem: "Sete dias ela levou para aprender sete passos. E na manhã do oitavo dia, quando acordou e viu a porta aberta, juntou sete passos e mais sete, atravessou o corredor, desceu a escada, cruzou o pátio e correu para a floresta à procura de sua Rainha" (Colasanti, 1979: 41). O sete "[...] indica o sentido de uma mudança depois de um ciclo concluído e de uma renovação positiva" (Chevalier \& Gheerbrant, 2019: 826). É transformação que ela conquista com a ajuda da Rainha, após um período de colonização e, consequentemente, de violências: "O sol ainda brilhava quando a corça saiu da floresta, só corça, não mais mulher. E se pôs a pastar sob as janelas do palácio" (Colasanti, 1979: 41).

A corça, da mesma maneira que a loba e a lua dos outros contos, é um ser não domesticado pelo homem da cultura capital-patriarcal. São animais selvagens e elementos inatingíveis que a autora inclui nos enredos. Essa preferência de Colasanti por personagens femininas que se "refugiam" no mais-que-humano e não buscam lidar com a situação a partir da sua própria "condição de mulher" nos faz questionar como fiz num outro artigo ${ }^{7}$ sobre os contos de fadas da autora - se há uma concepção de impotência diante do cerco patriarcal, sendo possível a resistência apenas pela via do maravilhoso. A questão central parece ser apontar a união ao igualmente oprimido para dar visibilidade a esse paralelismo histórico e para lembrar o lado instintual,

5 Utilizo essa expressão de Maria Mies e Vandana Shiva, por ela explicitar a relação violenta entre o capitalismo e o patriarcado, ambos contextos dos contos de Colasanti.

6 As personagens femininas dos contos de fadas de Marina Colasanti, geralmente, buscam a individuação, conceito junguiano que pode ser interpretado como "tornar-se um ser único", "tornar-se si mesmo".

7 Cf. Silva (2017). Nesse artigo, publicado nos anais do Seminário Internacional Fazendo Gênero 11 \& 13th Women's Worlds Congress, analiso, sob a perspectiva da ecocrítica feminista, os cenários distópicos nos quais se inserem as personagens femininas dos contos de fadas colasantianos "Debaixo da pele, a lua" e "Poça de sangue em campo de neve". Argumento, também, sobre as utopias enquanto possibilidades de liberdade dessas personagens. 
não domesticado, da mulher, que pode ser um mecanismo para a resistência de toda opressão voltada a ela, e não exatamente apontar caminhos para a superação dos dualismos e da violência estrutural do patriarcado por meios menos maravilhosos. Ao entrar no campo do essencialismo, tocando em binarismos questionáveis como homem/mulher, natureza/cultura, materialidade/corporalidade, humano/mais-quehumano, é inevitavelmente pisar em terreno minado. Colasanti constrói enredos e personagens que sugestionam uma leitura de cunho ecocrítico-feminista, e o seu principal mérito está em, de algum modo, levar-nos a pensar e a problematizar tais relações, sem com isso apresentar uma "solução" para os conflitos que se apresentam, no universo diegético e, tampouco, na realidade histórica. Na verdade, ela reinscreve algumas dessas dualidades. Além disso, é necessário sublinhar que a narrativa não considera a perspectiva do mais-que-humano e, embora eu tenha pontuado que há resistência da mulher e da natureza - pelo simples fato de se metamorfosearem -, o mais-que-humano é utilizado de modo acessório, servindo de instrumento para a personagem feminina resistir, o que não afasta a autora de uma consideração antropocêntrica dessa natureza.

Por outro lado, o final aberto, com a personagem "pastando" às vistas do opressor, é intrigante, e vejo-o como uma estratégia narrativa que subverte os finais fechados dos contos tradicionais, colocando quem o lê numa posição ativa, de construção de sentidos, além de não definir um confronto que provoque uma inversão da natureza sobre a cultura, o que, similarmente, ocorre em "Vermelho, entre os troncos", no (re)encontro da loba com o caçador, como demonstrarei adiante. Tais problemáticas, contudo, requerem um aprofundamento que foge do escopo deste trabalho, ${ }^{8}$ mas é conveniente destacar, nesta discussão, a rejeição da mulher ao corpo moldado pelo patriarcado e a ênfase que as narrativas dão à função da corporalidade/ materialidade nos processos subversivos.

Diferente de autoras de contos de fadas revisionistas como Angela Carter e Margaret Atwood, Marina Colasanti não subverte a ordem hegemônica dando voz às personagens femininas historicamente silenciadas pela tradição, uma vez que as narrativas são em terceira pessoa e, geralmente, com discurso indireto, como já destacado. No entanto, a agência que ela ignora, por intermédio do discurso, favorece pela visibilidade do aspecto material. Pelas transformações corporais metamorfizações -, as protagonistas resistem. Em "Debaixo da pele, a lua", a mulher tem a sua luz intensificada quando está com o homem rico, que desfaz o casamento: “'Essa mulher', pensou o homem cheio de desconfiança, 'vai acabar brilhando mais com sua luz do que eu com meu dinheiro"' (Colasanti, 1997: 47); e apagada quando o ladrão espera por muito brilho, já que iria explorá-la nas feiras. Essa é uma agência do corpo, uma intra-ação, no sentido de "[...] ações que podem surpreender, incomodar, aterrorizar ou desconcertar os humanos [...]" (Alaimo, 2017: 920). O corpo da mulher não é uma matéria passiva, base para interesses e apropriações masculinos, mas um corpo que "[...] tem suas próprias forças, interligadas e continuamente intra-agindo

8 Em minha pesquisa de doutorado - orientada pela professora Dra. Izabel Brandão -, à qual este artigo se vincula, teço reflexões mais aprofundadas acerca dessas questões. 
com matérias mais amplas e com forças sociais, econômicas, psicológicas e culturais [...]" (Alaimo, 2017: 921).

Rejeitada pelos homens, por não servir mais aos seus interesses, a personagem regressa à sua casa e, apenas nesse momento, apresenta uma postura de resistência dentro do padrão convencional. Além disso, o seu desejo é explicitado pela narrativa onisciente, que, via de regra, não dá espaço à discursividade da personagem feminina: "Trancou a porta, fechou bem fechado os postigos das janelas, vedou cada frincha. Que ninguém a visse" (Colasanti, 1997: 48). Até então, a mulher parecia aceitar, passivamente, todas as opressões. Nesse período, que prepara para o desfecho, ela (re)age, o que é sugerido pelos verbos na voz ativa: trancou, fechou, levantou-se, abriu, debruçou-se, montou.

Novamente sem qualquer verbalização, a expressão corporal dá as respostas e traça o destino da personagem. Mesmo fechando portas e janelas, o clarão sai pelas frestas e a mulher recebe mais uma visita, atraída por sua luz: uma dama num cavalo negro.

Antes mesmo que a mulher avançasse no umbral, sua pele estremeceu sobre a lua, sua luminosidade ondejou como reflexo de lago. E ela soube quem tinha vindo buscá-la.

O cavalo sacudiu a crina, impaciente. A dama debruçou-se, chamando-a. Sem voltar-se para olhar sua casa, a mulher estendeu a mão, e montou no cavalo da noite (Colasanti, 1997: 49).

O fenômeno que atraía os opressores, portanto, é realinhado, possibilitando a liberdade e o florescer do "fazer/ser" da mulher-lua, para usar uma expressão de

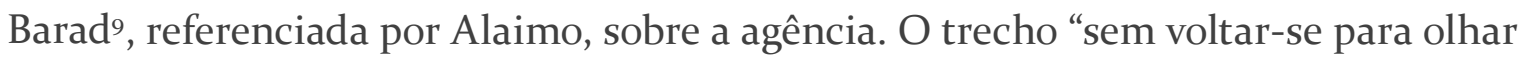
sua casa" evoca a não identificação da personagem com o espaço "cultural" onde se encontrava. Já o lugar "natural", para onde segue, é um campo aberto, indefinido, porém, claramente oposto ao padrão de natureza arquitetado pela cultura dominante.

Ainda que haja confronto direto entre a oprimida e o opressor, a narrativa não sugere uma leitura que sobreponha a natureza em relação à cultura, visto que não há uma vingança, exatamente, mas uma comprovação de que as naturezas, humana e mais-que-humana, reagem, como ocorre em "Vermelho, entre os troncos". No conto, o corpo abandonado na floresta torna-se alimento para lobas e lobos famintas/os. Uma loba leva o coração da mulher aniquilada para saciar sua única cria. Passado o tempo - demarcado pelo cair e brotar de folhas, sucessivas vezes -, o "mais belo" dos jovens cavaleiros, o feminicida, vai sozinho à caça. Na tentativa de capturar um javali, que resiste, o cavalo cai e o homem fica com a perna presa sob o animal.

Agora é na direção dele que o javali investe. Dele que não pode se levantar e que perdeu a lança. Dele indefeso. A cabeçorra baixa

9 Conforme a teoria de Barad, referenciada por Alaimo, "[a] agência não é absolutamente um atributo - é um 'fazer/ser' em sua intra-atividade" (919). 
se aproxima, quase o lança com suas presas amarelas, quando um movimento novo, um ruído vindo da floresta, interrompe os guinchos. Um instante de hesitação, a cabeçorra se volta e o javali foge, abandonando sua presa (Colasanti, 2009: 74, ênfases minhas).

Os períodos em destaque são irônicos: sem ferramentas, o cavaleiro é tão indefeso quanto a mulher que se banhava, nua. A ecofeminista Carol Adams, em $A$ política sexual da carne, argumenta que os animais, de fato, carnívoros, matam suas presas, consumindo-as logo em seguida, com o auxílio apenas de garras e dentes. Por outro lado, baseando-se no poeta Plutarco, em seu "Ensaio sobre o consumo de carne", defende que "[n]ós somos desprovidos de meios corporais para matar e desmembrar os animais que comemos; precisamos de equipamentos" (Adams, 2012: 91). Sem a lança, o caçador não ataca, não mata e não come o animal mais-quehumano.

No momento do ataque à mulher, ele está provido de equipamentos. Porém, mata-a, mas não a leva para o castelo, como faz com a carne das outras caças. Adams trabalha com o conceito de referente ausente, para tratar da ligação entre a violência contra as mulheres e a voltada aos animais. Segundo ela, para que a carne "consumível" exista, os animais, com seus nomes e seus corpos, tornam-se ausentes. Nesse sentido, há bife no lugar de boi; bacon no lugar de porco; asa "de" galinha ao invés de asa "da” galinha, entre outras renomeações e substituições que mascaram a morte e o retalhamento do animal. Há, assim, três modos pelos quais o maisque-humano torna-se referente ausente, ainda na concepção de Adams: a literal, que diz respeito ao animal morto; a conceitual, que está relacionada à linguagem, i. e., à renomeação; e a metafórica, em que "[...] os animais se tornam metáforas para descrever as experiências humanas” (Adams, 2012: 79). A mulher caçada, do conto de Colasanti, é um exemplo de referente ausente metafórico, assim como a mulher-lua, que, embora não seja vinculada a um animal, é acorrentada no pé da mesa e ameaçada de exploração em feiras. Mesmo antes das metamorfoses, portanto, mulheres e animais recebem tratamentos opressivos, na (i)lógica capital-patriarcal.

As opressões dirigidas aos animais e às mulheres, ainda na esteira de Adams, são respaldadas pela objetualização, que "[...] permite ao opressor ver outro ser como objeto" (Adams, 2012: 86). As três mulheres representadas nos contos - do mesmo modo que o mais-que-humano a elas vinculado - são tratadas como objetos que existem para servir aos interesses dos homens pertencentes à cultura. Dessa maneira, não há qualquer manifestação ética no contato deles com esse outro objetualizado. Enquanto as mulheres das narrativas manifestam uma corporalidade em comunhão com a carnalidade mais-que-humana, os homens representados assumem um lugar de desconexão e de superioridade. Eles agem como se não integrassem o ambiente e fossem superiores aos demais seres que habitam os espaços onde também vivem e por onde circulam. É evidente o interesse de Colasanti na crítica ao sistema dominante e ao protagonismo do modelo de masculinidade legitimado por esse contexto, mas 
também é notório, como já explicitado, o caráter essencialista na construção da personagem apenas presa a esse padrão.

Nos contos, os homens domestificam alguns animais - cães e cavalos, sobretudo -, que auxiliam na captura e na morte de outros, considerados selvagens. No conto "Vermelho, entre os troncos", é em razão da personagem masculina e de sua atividade de caça que os cães atacam o javali, e esse, por sua vez, se volta contra o cavalo.

O cavaleiro firma a lança na mão, esporeia o cavalo. Cães avançam sobre o javali, que se esquiva de um lado a outro, tentando escapar. A ponta de ferro desce com fúria, resvala no pelo hirsuto, se mancha de sangue. $\mathrm{O}$ animal se torce enfurecido, se volta aos guinchos. Ataca. As presas dilaceram as patas do cavalo. O cavaleiro crava as esporas. O cavalo empina, o javali ataca pelo lado, o cavaleiro se volta na sela, desequilibra o cavalo. O cavalo cai. E por baixo do cavalo, sobre o seu peso, está a perna do cavaleiro (Colasanti, 2009: 74).

Ao salientar esse confronto, não pretendo sugerir que conflitos dessa natureza não existam no mundo mais-que-humano. A questão a ser pontuada é a intervenção do homem e as consequências que essa atitude egocêntrica, inevitavelmente, traz. Nos contos "Entre as folhas do verde O" e "Debaixo da pele, a lua", parecem não ocorrer movimentos transcorpóreos entre os homens e a natureza mais-que-humana. As personagens masculinas oprimem as mulheres, a mulher-lua e os animais, mas não demonstram reações diante da inseparabilidade da corporalidade humana com a natureza ou com o ambiente, discutida por Alaimo. As personagens femininas resistem, subvertem, mas não travam contato direto com os opressores. Já o conto "Vermelho, entre os troncos" pode ser interpretado como uma exceção. No instante em que a perna do homem fica presa sob o cavalo, "[...] algo se move na floresta. Um graveto estala, próximo. À sua frente, uma moita estremece, as folhagens se abrem devagar. E saindo do escuro verde, como se saísse da água uma loba avança pousada na sua direção. Uma loba toda branca como a lua" (Colasanti, 2009: 74).

É assim, de forma aberta a inúmeras possibilidades de leitura, que o conto termina. Em outro momento, a narrativa descreve a mulher da seguinte maneira: "Na escuridão que se adensa, o corpo estendido é branco como a lua" (Colasanti, 2009: 72). ${ }^{10}$ Em outras palavras, a loba é a mulher caçada, que "reviveu" no animal maisque-humano após o filhote fêmea ter comido o seu coração. Esse conto difere dos demais por colocar a vítima metamorfoseada diante do opressor, numa situação de vulnerabilidade desse último. No entanto, Colasanti não conclui a narrativa fechando

10 Com relação ao adjetivo que caracteriza a loba, aproximando-a da mulher, é necessário pontuar o protagonismo que a autora dá à mulher branca, o que ocorre também nos demais contos, já que há uma mulher luminosa, por ter a lua sob a pele, e outras cujo corpo é todo branco, como já descrito. Essa questão relativa à interseccionalidade implica uma discussão necessária, mas, neste momento, não poderá ser aprofundada, porque o enfoque deste artigo é outro. 
a interpretação num revide - embora não anule essa possibilidade. Ao sugerir uma reação diferente de uma reprodução da violência de base patriarcal, a autora viabiliza a compreensão de um mundo mais-que-humano que não representa o eterno oposto da cultura, guerreando pela supremacia. A corporalidade do homem, nesse caso, é inseparável do ambiente, considerando que a sua matéria sofre as reações de um desequilíbrio ecológico que ele próprio provocou. Com Brandão, compreendo, baseada no conceito de transcorporalidade de Alaimo, a afinidade entre a natureza e o humano, ainda que estejam, "[...] paradoxalmente, em conflito, em movimentos em que a agência está em constante (intra)movimento” (Brandão, 2017: 972).

De fato, não há, nas narrativas analisadas, “[...] transformação dos dualismos marcados pelo gênero - natureza, cultura, corpo, mente, objeto, sujeito, recurso, agenciamento e outros [...]" propostos por Alaimo (2017: 912), tendo em vista que as representações da cultura e do homem não são ressignificadas; nem a união, em "naturezasculturas", de “[c]arne e significante, corpos e palavras, histórias e mundos [...]", defendida por Haraway (2017: 74). Entretanto, os contos evidenciam um uso do essencialismo atribuído à ligação da mulher com a natureza - em contraposição à cultura vinculada, exclusivamente, ao homem - como estratégia que realinha essa ligação, conferindo-lhe um sentido afirmativo, na medida em que visibiliza a importância da materialidade nos processos de resistência e subversão. Além disso, ressignifica o conceito de natureza - ainda que prevaleça a oposição com a cultura, locus sine qua non da opressão -, representando-a como um espaço ativo, constituído por agenciamentos mais-que-humanos. Colasanti, todavia, trata dessa materialidade desconsiderando a discursividade, o que pode ser lido como uma espécie de crítica à supremacia do discurso pelo feminismo construcionista e à consequente negação do corpo biológico.

\section{Bibliografia}

ADAMS, Carol J. (2012). A política sexual da carne: a relação entre o carnivorismo e a dominância masculina. Tradução Cristina Cupertino. 1. ed. São Paulo: Alaúde Editorial.

ALAIMO, Stacy. (2017). "Feminismos transcorpóreos e o espaço ético da natureza". Tradução Susana Funck. Rev. Estud. Fem. [online], vol.25, n.2: p. 909-934.

BRANDÃO, Izabel. (2003). "Ecofeminismo e literatura: novas fronteiras críticas". In: BRANDÃO, Izabel \& ZAHIDÉ, Muzart (Orgs.). Refazendo nós: ensaios sobre mulher e literatura. Florianópolis: Ed. Mulheres; Santa Cruz do Sul: EDUNISC. p. 461-473. 
BRANDÃO, Izabel. (2017). "A propósito de 'feminismos transcorpóreos e o espaço ético da natureza', de Stacy Alaimo". Estudos Feministas, Florianópolis, 25 (2): p. 961974, maio-agosto.

CHEVALIER, Jean \& GHEERBRANT, Alain. (2019). Dicionário de Símbolos: mitos, sonhos, costumes, gestos, formas, figuras, cores, números. 33. ed. Tradução Vera da Costa e Silva et al. Rio de Janeiro: José Olympio.

COLASANTI, Marina. (1979). Uma ideia toda azul. 16. ed. Rio de Janeiro: Nórdica.

COLASANTI, Marina. (1997). Longe como o meu querer. São Paulo: Ática.

COLASANTI, Marina. (2009). Do seu coração partido. São Paulo: Global.

FUNCK, Susana Bórneo. (2016). "Além do bastidor: personagens femininas de Marina Colasanti”. In: FUNCK, Susana Bórneo. Crítica literária - uma trajetória. Florianópolis: Insular. p. 333-340.

FUSS, Diana. (2017). "O 'risco' da essência”. Tradução Ildney Cavalcanti e Amanda Prado. In: BRANDÃO, Izabel et al. (Org.). Traduções da cultura: perspectivas críticas feministas (1970-2010). Florianópolis: EDUFAL, Editora da UFSC. p. 362-397.

GAARD, Greta. (2017). "Novos rumos para o ecofeminismo: em busca de uma ecocrítica mais ecofeminista”. Tradução Izabel Brandão e Marina Verçosa de Andrade. In: BRANDÃO, Izabel et al (Orgs.). Traduções da cultura: perspectivas críticas feministas (1970-2010). Florianópolis e Maceió: Mulheres, Edufsc e Edufal. p. 783-818.

HARAWAY, Donna. (2017). "O manifesto das espécies companheiras - cães, pessoas e alteridade significante [fragmento]”. Tradução Ildney Cavalcanti e Amanda Prado. In: BRANDÃO, Izabel et al. (Org.). Traduções da cultura: perspectivas críticas feministas (1970-2010). Florianópolis: EDUFAL, Editora da UFSC. p. 722-745.

JUNG, Carl Gustav. (1984). "Instinto e inconsciente”. In: JUNG, Carl Gustav. A dinâmica do inconsciente: A natureza da psique. Tradução Pe. Dom Mateus Ramalho Rocha, OSB. Petrópolis: Vozes. p. 72-82.

MENDOZA, Breny. (2017). "A epistemologia do sul, a colonialidade de gênero e o feminismo latino-americano". Tradução Laureny Aparecida Lourenço da Silva. In: BRANDÃO, Izabel et al. (Org.). Traduções da cultura: perspectivas críticas feministas (1970-2010). Florianópolis: EDUFAL, Editora da UFSC. p. 753-776.

MIES, Maria \& SHIVA, Vandana. (1993). Ecofeminismo. Tradução Fernando Dias Antunes. Lisboa: Instituto Piaget. p. 9-34. 
MOI, Toril. (2017). "Introdução: Quem tem medo de Virginia Woolf? Leituras feministas de Woolf”. Tradução Izabel Brandão. In: BRANDÃO, Izabel et al. (Org.). Traduções da cultura: perspectivas críticas feministas (1970-2010). Florianópolis: EDUFAL, Editora da UFSC. p. 280-303.

ORTNER, Sherry B. (2017). "Está a mulher para o homem assim como a natureza para a cultura?” Tradução Cila Ankier e Rachel Gorenstein. In: BRANDÃO, Izabel etal. (Org.). Traduções da cultura: perspectivas críticas feministas (1970-2010). Florianópolis: EDUFAL, Editora da UFSC. p. 91-123.

RUSSO, Mary. (2000). O grotesco feminino: risco, excesso e modernidade. Tradução Talita M. Rodrigues. Rio de Janeiro: Rocco.

SILVA, Edilane Ferreira da. (2017). "Distopia e utopia na narrativa maravilhosa de Marina Colasanti - um diálogo com a ecocrítica feminista”. Seminário Internacional Fazendo Gênero 11 E 13th Women's Worlds Congress. Florianópolis: UFSC. Disponível em: < http://www.en.wwc2017.eventos.dype.com.br/resources/anais/1503884896_ ARQUIVO_Artigocompleto[final2].pdf>. Acesso em: 29 nov. 2018.

SPIVAK, Gayatri Chakravorty. (2010). Pode o subalterno falar? Tradução Sandra Regina Goulart Almeida, Marcos Pereira Feitosa e André Pereira Feitosa. Belo Horizonte: Editora UFMG.

Recebido em 30/05/2020.

Aceito em 20/06/2020. 